\title{
Tirios y Troyanos: sindicatos y partidos durante el gobierno de Lula y Kirchner
}

\author{
Tyrian and Trojan: Unions and Parties During the Government of Lula and \\ Kirchner
}

\section{Juan Lucca}

Juan Lucca es Investigador del Consejo Nacional de Investigaciones Científicas y Técnicas y docente en la Universidad Nacional de Rosario, Argentina.

E-mail: juanbautistalucca@gmail.com

\section{resumen}

La llegada al gobierno a inicios del siglo XXI de partidos de base sindical, como el Partido de los Trabajadores (PT) en Brasil y el Partido Justicialista/Frente Para la Victoria (PJ/FPV) en Argentina, trajo aparejada la reincorporación de los trabajadores y los sindicatos a la arena política por un lado y, por el otro, la amalgama de un entramado discursivo de anteposición al pasado reciente, sus actores y valores. Bajo estas condiciones se produjo un proceso de (re)construcción identitaria de ambas fuerzas políticas con el mundo del trabajo y sus actores organizados (especialmente la CUT en Brasil y la CGT en Argentina). En este sentido, tomando en cuenta los discursos de Lula y Kirchner, así como también documentos y entrevistas a los principales líderes de ambos partidos y organizaciones sindicales afines, se observará en qué medida se produce durante el mandato de gobierno de ambos presidentes una convergencia de cosmovisiones respecto a la definición de quiénes están fronteras adentro ("nosotros") y fronteras afuera ("otros") de este nuevo vínculo entre el mundo partidario y sindical.

\section{palabras clave}

Kirchner / Lula / sindicatos / partidos / identidades

\section{summary}

The Partido de los Trabajadores (PT) in Brazil and the Partido Justicialista/Frente Para la Victoria $(\mathrm{PJ} / \mathrm{FPV})$ in Argentina are both labor based parties that reached the government under the Latin American "left turn" on the XXI Century. They specially undertook a discursive position that counteracted with the recent past, its actors and values, and that reintroduced workers and trade unions in the political arena. In order to do that, they put into play a whole discursive framework from which carried out the (re)constitution of a new identity with the CUT (Brazil) and the CGT (Argentina) respectively. In this regard, taking into account the public positions of Lula and Kirchner, as well as all documents and interviews with key leaders from both parties and trade unions, this paper will be focused on analyze if there is an identity convergence of worldviews, especially in the definition of those who are borders inside ("we") and outside borders ("others").

\section{keywords}

Kirchner / Lula / trade unions / political parties / identity 


\section{Introducción}

En general, la problemática de las identidades es un prisma inusual dentro del estudio de los partidos políticos contemporáneos; sin embargo, en esta investigación se sostiene que todo actor que tiene -o busca tener- incidencia en la arena política debe posicionarse públicamente, configurando una identidad política, que se evidencia en las prácticas y las significaciones que le otorga a éstas.

Si recuperamos desarrollos previos sobre la noción de identidad, es posible señalar que dicha noción es un proceso de bricolaje con múltiples puntos de partida y de llegada, una construcción relacional constituida por un entramado de prácticas materiales y discursivas en las que se define quiénes forman parte del "nosotros" y los "otros" (Tilly, 2005: 209-10; Kraay, 2007: 3). Por ello, en este estudio se observará cómo se configura esta frontera identitaria producto del entrecruzamiento de tres planos discursivos -el partidario, el de las organizaciones sindicales y el de la figura presidencial-para advertir si existe o no una cosmovisión de sentidos sobre una de las definiciones centrales en torno a la identidad: quién es el otro y quiénes somos nosotros. Ahora bien, aunque la construcción de identidades puede observarse en múltiples planos (individual, colectivo, axiológico, temporal, etc.) en este artículo se focalizará exclusivamente en identificar cómo se produce la construcción del otro-nosotros en términos actorales.

En cuanto al enfoque metodológico que se utilizará en el presente estudio, será de tipo histórico comparado u orientado a casos, construido a partir de la delimitación de un fenómeno particular: el vínculo de tipo identitario de cada uno de los presidentes (Néstor Kirchner en Argentina entre 2003-2007 y Lula da Silva en Brasil entre 2003-2006), sus respectivos partidos (Partido de los Trabajadores -PT-y Partido Justicialista / Frente Para la Victoria -PJ/FPV-) y las organizaciones sindicales mayoritarias (la Central Única de Trabajadores -CUT- y la Confederación General del Trabajo -CGT-). La selección de estos casos radica en tener en cuenta los siguientes criterios: a) partidos con vínculos históricos con el mundo sindical que; b) llegaron al poder en el siglo XXI en el marco del inicio del "giro a la izquierda latinoamericano"; y c) se posicionaron a favor de la recuperación del mundo del trabajo como principal eje articulador del entramado social (Murillo, 2005; Levitsky y Mainwaring, 2007). ${ }^{1}$ Ahora bien, el recorte temporal en el primer mandato de Lula y el mandato de Néstor Kirchner no sólo se fundamenta en la centralidad que podría adquirir el vínculo partido-sindicalismo en esta nueva escena política, sino también en la necesidad de diferenciar estos casos - a priori similares- en sus estrategias identitarias (afirmación del nosotros, diferenciación con otro, u ambos). Asimismo, recortar este período permite aprehender un instante de solidez de un constructo identitario que generalmente es voluble y cambiante ya que, en Argentina, la llegada de Cristina Fernández de Kirchner a la presidencia en 2007 y la "crisis del campo" en 2008 modificaron la relación partido-sindicato por un lado; en Brasil, por el otro, el enjuiciamiento de los dirigentes del PT por el Mensalão y la nueva dinámica de socios partidarios durante el segundo gobierno de Lula pusieron en entredicho una larga vinculación entre Lula, el PT y la CUT. Por tales motivos, aprehender la dinámica que adquiere la configuración de la 
identidad partidario-sindical en este período resulta vital para poder dar cuenta del giro real hacia el diálogo y reconfiguración de lo social que inauguran estos gobiernos en la región, independientemente de sus múltiples torsiones y avatares posteriores (Lucca, Benetti e Iglesias, 2017).

En términos metodológicos, los dos partidos seleccionados (PT y PJ), en su relación con el mundo obrero sindical (CUT y CGT), en el marco del gobierno Lula (2003-2006) y Kirchner (2003-2007), configuran dos casos de estudio de enorme relevancia para observar los contrastes y similitudes que adquiere la construcción de las fronteras identitarias (nosotros-otros). Para realizar esta comparación, las fuentes primarias utilizadas fueron: 1) entrevistas no estructuradas a dirigentes sindicales y partidarios; 2) los principales documentos institucionales de los partidos y sindicatos en cuestión; y 3) la totalidad de los discursos presidenciales durante el período de análisis.

La hipótesis central de este estudio sostiene que en el caso argentino se trataría de una reconstrucción o intento de retorno a un vínculo identitario previo basado en la identificación clara del adversario, habida cuenta del cambio en la relación entre peronismo y sindicalismo durante la década de 1990 (Levitsky, 2005), en tanto que en el caso brasileño se trataría de una estructuración identitaria que históricamente alcanza su apogeo, ya que a la convergencia de cosmovisiones sobre quién es el "otro" se le añade también la de quiénes forman el "nosotros" (Radermacher y Melleiro, 2007).

\section{Marco histórico comparativo}

Históricamente ambos casos seleccionados comparten como semejanza de partida el ser fuerzas partidarias con bases en el movimiento obrero; sin embargo, en el derrotero histórico de cada una de las organizaciones partidarias y sindicales, así como también en los avatares y vicisitudes en la (re/de) construcción del vínculo durante el período estudiado, se observan comparativamente claros contrastes de contextos (Skocpol y Sommers, 1994).

En cuanto al origen del vínculo partido-sindicato, en el caso argentino la relación PJ y CGT se remonta al apogeo de la matriz Estado-céntrica de corte nacional y popular bajo el liderazgo de Juan D. Perón; en el caso brasileño, los intentos de Getulio Vargas por vincular política y sindicalismo en el contexto de industrialización por sustitución de importaciones quedaron truncos, y solamente la partidización del mundo sindical pudo lograrse a mediados de la década de 1970 cuando el propio sindicalismo (Novo Sindicalismo) pudo liderar sus pretensiones políticas, por ejemplo, fundando el PT (Lucca, 2011).

En las décadas siguientes a la redemocratización, en Argentina tanto la "renovación peronista" como el "peronismo menemista" y sus políticas de transformación del mundo del trabajo, produjeron una desindicalización del PJ que fue en menoscabo de la histórica vinculación partidario-sindical, dejando el vínculo cuasi inerte o con un sentido meramente utilitario (Levitsky, 2005). En Brasil, la situación fue diferente, puesto que durante la década de 1980 y 1990 tanto Lula, como el PT y la CUT se entronizan como los referentes del discurso opositor al neoliberalismo "a 
la brasileña", produciendo una fuerte sinergia discursiva, a pesar de las solapadas tensiones por la creciente pretensión electoral de Lula y el PT (Lucca, 2012).

Ahora bien, a inicios del siglo XXI se produce una reconfiguración de la escena política con la victoria de Lula en Brasil (2003-2006) y Néstor Kirchner en Argentina (2003 y 2007). Si nos detenemos en detalle a revisar el marco histórico en el que se inserta esta comparación, es posible señalar que, en Argentina, la ausencia originaria de legitimidad electoral del presidente Néstor Kirchner fue suplida inicialmente por una apelación directa hacia la ciudadanía bajo el sintagma "los argentinos y argentinas", configurándolo como un "liderazgo de audiencia" (Rodríguez, 2014). En paralelo a esta estrategia, se fue configurando el kirchnerismo como expresión político-partidaria con pretensiones electorales exitosas, aupado en las victorias electorales en 2003 y 2005, la opinión pública favorable al gobierno, los apoyos sociales y políticos que iban desde los sectores "transversales" al retorno hacia los "peronistas tradicionales" o incluso a "radicales K" a final del período, entre otros.

Correlativamente a este proceso de legitimación presidencial bajo un liderazgo de audiencia y la constitución progresiva del kirchnerismo como fuerza política, se produce la reconfiguración del vínculo partido-sindicato de estirpe peronista (Iglesias y Lucca, 2016). En un primer momento, durante el año 2003 y 2004, esta relación tuvo diversas experiencias frustradas: porque el MTA de Moyano había apoyado en las elecciones de 2003 a Rodríguez Saa; porque Kirchner (incluso a inicios de la presidencia) estableció un diálogo preferencial con la CTA, lo cual era una amenaza clara de querer romper la tradición peronista de apoyarse en la CGT; porque la CGT y el PJ se encontraban fuertemente divididos entre quienes eran deudores y acreedores de las experiencias políticas desarrolladas durante la década previa. En un segundo momento, hacia 2005, el panorama comienza a cambiar, producto de la reunificación de la CGT bajo el dominio de Moyano, el fortalecimiento de Kirchner y su reinserción en el PJ al deshacerse de todo vestigio duhaldista, y la recuperación del mundo del trabajo que revigorizó las organizaciones sindicales. Sin embargo, este nuevo entendimiento partidario sindical que se da a partir de 2005 entre Kirchner y Moyano, el PJ/FPV y la CGT, se configura a partir de una necesidad estratégica de tipo coyuntural, que aunque presenta cierta rémora del pasado, no retoma plenamente ninguna de las morfologías peronistas precedentes. Esto configura un constructo identitario incipiente, que difícilmente pueda sobrevivir a la eclosión política y sindical que produjo el "conflicto del campo" en el año 2008 o los intentos posteriores de Cristina Fernández de Kirchner por desplazar a Moyano como secretario general de la CGT y reconfigurar un nuevo vinculo partidario-sindical (Lucca, 2014).

En el caso de Brasil, cabe señalar que el primer período de gobierno de Lula da Silva en la presidencia supuso una influencia del mundo sindical en la esfera público-política como no hubo anteriormente en la historia brasileña. Esta "revolución sindical por las urnas" fue el resultado esperable de una trayectoria común y una cosmovisión política compartida entre el PT y la CUT durante los años previos. Esto se tradujo en una fuerte sintonía dirigencial entre ambas organizaciones, 
ejemplificado en la destacable presencia de ex sindicalistas en los cargos ministeriales cuando Lula obtuvo la presidencia, la fuerte presencia de petistas dentro de la central y el flujo constante de dirigentes sindicales que ingresan a la actividad partidaria en el marco del PT.

Este entendimiento y afinidad entre el PT en el gobierno y la CUT tomó mayor entidad en las instancias en las que ambos debían anteponerse a una tercera fuerza externa desafiante de la continuidad del proyecto petista, como los medios de comunicación y los partidos opositores durante la crisis del Mensalão en 2005 o el PSDB y sus fuerzas políticas de apoyo durante las elecciones de 2002 y 2006.

En cambio, durante los momentos en los que el gobierno quiso introducir reformas y cambios que impactaban directamente en el mundo del trabajo -como la reforma previsional o de la estructura sindical- la tensión entre el gobierno, el PT y la CUT se hizo evidente, fortaleciendo inclusive las voces de los sectores minoritarios y/o radicalizados de izquierda que otrora formaban parte de la entente partidario-sindical tras Lula, como es el caso de quienes formaron CONULTAS y la INTERSINDICAL en el plano sindical o el PSOL en el partidario (Lucca, 2013). Ahora bien, esta entente Lula-PT-CUT difícilmente habría de mantenerse cohesionada e imbricada con tal nivel de fortaleza más allá del primer gobierno de Lula (Amaral, 2011) puesto que, en primer lugar, la grave crisis del PT por las renuncias, enjuiciamiento y posterior encarcelamiento de los principales dirigentes del partido por el Mensalão no sólo horadaba la organización partidaria y el gobierno sino que también ponía en entredicho ciertos principios y valores compartidos con los sectores sociales de apoyo entre los que se encontraba la CUT; en segundo lugar, porque la vocación electoral en crecimiento -a pesar de la crisis interna del PT - alentaba tanto la personalización política en la figura de Lula más allá del partido, dando espacio inclusive a la incorporación de nuevos socios partidarios como el PMDB, que desvirtuaban parte del entramado identitario precedente en el que se vinculaban partido, gobierno y sindicatos (Amaral, 2009).

Por ende, tanto en Argentina como en Brasil, durante el período de gobierno de Kirchner y el primer mandato de Lula, se pone en juego claramente una compleja dinámica de configuración y reconfiguración de las identidades políticas, especialmente en lo que atañe a la dimensión partidario-sindical de las fuerzas políticas estudiadas. Por ello, resulta vital comprender en profundidad qué incorporan fronteras adentro de sus identidades o emplazan por fuera de sí. Es evidente que la multidimensionalidad de la construcción identitaria ofrece múltiples aristas desde donde observar las cosmovisiones compartidas en esta relación tripartita Presidente-Partido-Sindicato; sin embargo, es claramente en el plano de los actores donde puede observarse con mayor claridad quiénes somos "nosotros" y quiénes son los "otros".

\section{Análisis del caso argentino}

a) Nosotros Actoral:

Para analizar quién es el "nosotros" en el caso de Argentina, cabe señalar que existe en el discurso de Kirchner una gran cantidad de interlocutores con esta cua- 
lidad, por lo que se focalizará en: a) los que refieren al mundo de la política (especialmente los partidos); y b) al mundo del trabajo (trabajadores y sindicatos).

En cuanto a los partidos, puede observarse que Kirchner, al colocarse como heredero de la crisis de representación y el estallido social de 2001, se posicionaba en un lugar que trascendía las siglas tradicionales buscando integrarlas pragmáticamente según la coyuntura. ${ }^{2}$

En la mirada de los dirigentes partidarios sobre los partidos valorados positivamente, aquellos que provenían del justicialismo reconocieron la importancia de esta sigla en la construcción de la legitimidad presidencial. ${ }^{3}$ Esta mirada de valorización del justicialismo se encuentra también en los dirigentes sindicales de la CGT, que reconocen que la debilidad inicial de Kirchner sólo podía ser superada gracias al poder de "movilización y estructura" que brindaban los intendentes del conurbano bonaerense. ${ }^{4}$

Si se analizan las referencias actorales dentro del mundo laboral, Kirchner asignaba un rol central a los trabajadores, ya que eran considerados como los principales engranajes de la recuperación del país y los actores a quienes debía devolverles el "respeto de la sociedad". Según Gerardo Aboy Carlés (2006: 191), en este caso se pone de manifiesto la estrategia discursiva kirchnerista de elaboración de una promesa reparadora de una sociedad dañada para incluir en un "todo común" (un "nosotros" tal y como se viene postulando aquí) a los excluidos, renegados y reprobados en el "pasado siniestro", como es en este caso los trabajadores.

La mirada de los dirigentes partidarios de extracción peronista en relación con los trabajadores coincide con la valoración positiva del presidente, al punto que algunos exponentes del FPV como Antonio Alizegui (2010) llegan a señalar al ser entrevistados que "los trabajadores pasan a ser la fuente de nutrición de este gobierno, porque sin la pata trabajadora no se puede". Otros exponentes dentro del arco peronista no kirchnerista, si bien reconocen la centralidad de los trabajadores para el gobierno de Kirchner, aducen que este elemento es un aspecto histórico del peronismo y no un nuevo añadido de este gobierno. ${ }^{5}$

Esta centralidad de los trabajadores en el peronismo es fuertemente apreciada por la gran mayoría de los sindicalistas entrevistados como uno de los valores rectores del "peronismo" en sus múltiples expresiones, y especialmente en el marco del gobierno Kirchner, como se evidencia a continuación:

Esa alianza estratégica indica que si hay un gobierno nacional y popular te tenés que apoyar en los trabajadores. Eso, a medida que se fue profundizando, de ser implícita se fue haciendo cada vez más explícita. Y yo creo que terminó de hacerse visible cuando apareció el enemigo enfrente con el "conflicto del campo" (Piumato, 2009).

En lo que atañe a los sindicatos, en términos cuantitativos el gremio de la construcción (UOCRA), la Central de Trabajadores Argentinos (CTA) y la CGT ocupaban un lugar central y positivo en los discursos de Kirchner. En el caso de la UOCRA, Kirchner valoraba la colaboración de este sindicato en la obtención del fin trascendente de "levantar el país"; en el caso de CTA la valoración positiva era 
el resultado de un entendimiento sobre valores comunes y el vínculo con su dirigencia sindical; en tanto que con la CGT se plantea justamente el entendimiento dirigencial (especialmente con Hugo Moyano) en el marco de la coyuntura de reestructuración del liderazgo en la CGT. ${ }^{6}$

Si se observa la mirada de los dirigentes partidarios en el reconocimiento de las organizaciones sindicales y sus líderes, uno de los primeros aspectos que sobresale es la valoración positiva del sindicalismo en su conjunto, especialmente desde la recuperación de la actividad laboral a partir de 2002 y su reingreso en la arena económica, productiva e inclusive en la política partidaria. ${ }^{7}$

Sin embargo, esta mirada panorámica favorable a los sindicatos en su conjunto encubre una disparidad de opiniones dentro de los líderes peronistas. En primer lugar, es escasa la valoración del gremio de la construcción (UOCRA), y en contrapartida se realza más a los sectores vinculados al Sindicato de Camioneros que dirige Moyano. En segundo lugar, se establece la distinción entre dirigentes sindicales enrolados en el Movimiento de Trabajadores Argentinos (MTA) y aquellos a los que se conoce popularmente como "los gordos", vinculados con el menemismo. ${ }^{8}$ En tercer lugar, es posible encontrar en la mirada de los dirigentes partidarios entrevistados una mayor referencia hacia Moyano como exponente de las expresiones sindicales cegetistas más cercanas al gobierno, a pesar de no ser un kirchnerista de la primera hora. ${ }^{9}$

Si se toma en cuenta la mirada de los dirigentes sindicales entrevistados acerca de la inclusión/exclusión del sindicalismo dentro del "nosotros actoral", se pone en evidencia una cercanía manifiesta con el gobierno, construida gracias a las políticas económicas, productivas y laborales favorables al mundo del trabajo y sindical que llevó adelante desde 2003, al desarrollo de una cosmovisión ideológica (principalmente con la CTA), y la puesta en práctica de ardides de la tradición peronista como por ejemplo la idea de que "una vez pasada la elección el que ganó conduce, el que perdió acompaña". ${ }^{10}$

\section{b) Otros Actorales:}

Para distinguir a los actores que constituían los "otros" a la tríada peronista (gobierno, sindicatos y partido) es necesario destacar tanto la diversidad de antagonistas, como también la intensidad con la que se plantea este encono. En este sentido, si se toma en cuenta el discurso de Kirchner, es posible reconocer cuatro actores valorados negativamente: los dirigentes políticos previos a su gobierno; los organismos multilaterales de crédito; los grupos económicos; y por último, los medios de comunicación.

Las críticas de Kirchner respecto de la clase política en su conjunto se basaban en el tipo de políticas públicas llevadas adelante, la corrupción que alentaron o permitieron, los valores que orientaron su acción (falta de coraje, decisión y responsabilidad frente a la crisis, preferencia por lo extranjero, etc.), entre otros. ${ }^{11}$ Ahora bien, cuando se identifica personalmente a aquellos que Kirchner emplaza en su "otros actoral" es interesante notar que en su totalidad éstos eran políticos de alto rango que se desempeñaron durante la década del noventa: Carlos Menem, 
Fernando De la Rúa, Domingo Cavallo, Ricardo López Murphy y Eduardo Duhalde.

Esta mirada negativa sobre los dirigentes políticos, especialmente focalizada en Menem, tiene una fuerte adhesión por gran parte los dirigentes partidarios, que lo critican por la implantación y desarrollo de un modelo socioeconómico de corte neoliberal; la fuerte concentración del poder en la figura del presidente; la cooptación de la dirigencia sindical para debilitar el carácter reivindicativo de las organizaciones enroladas en la CGT; y el socavamiento de las organizaciones sindicales dentro del justicialismo.

Si se observa la evaluación que la dirigencia sindical posee del ex mandatario riojano, se advierten dos posiciones bien diferenciadas. Por un lado, están quienes lo critican por haber llevado adelante un modelo neoliberal que destruyó las fuentes genuinas de trabajo y flexibilizó los derechos laborales, por haber impulsado una política de debilitamiento y atomización de las organizaciones sindicales y de cooptación de sus dirigencias, de desideologización del peronismo y el movimiento obrero, tal y como puede verse condensado en el siguiente fragmento:

Quién iba a pensar que Menem, con el "no los voy a defraudar", "el salariazo" y todo eso que hizo que la gente confiara, en cambio, vino con el gran contrabando ideológico. Los primeros que lo percibimos fue el movimiento sindical, y salimos a resistirlo una parte, y fractura la CGT. Como siempre hay un movimiento sindical que es funcional a esto (...). Además hay un tema clarito para vaciar ideológicamente al peronismo, que fue el usar las fechas históricas del peronismo para vaciar de derechos a los trabajadores. Un 17 de Octubre se reglamentó el derecho de huelga, un $1^{\circ}$ de Mayo se dictaron normas flexibilizadoras del trabajo (Piumato, 2010).

Por otro lado, se encuentran quienes desdibujan el tinte negativo hacia el ex mandatario al señalar que, durante su gestión, sus políticas públicas no eran advertidas como peligrosas para la sociedad, los trabajadores y las dirigencias sindicales, exculpándolos por ende del devenir posterior de la situación argentina. Esta postura se evidencia en las declaraciones vertidas por exponentes como Susana Rueda, perteneciente al sector de "los gordos", en el siguiente fragmento:

Recordarás aquel slogan, en la época de De la Rúa, donde aparecían distintos dirigentes sindicales: Lorenzo Miguel, que todavía vivía, Daer y unos otros cuantos, y decían "estos son los responsables de lo que le pasa al país"; como que burócratas o no, gente que quiso conservarse, más allá de lo que hubiesen querido sus trabajadores o no, votarlos, los votaron. Lo cierto es que no podíamos ser los responsables de lo que le ocurría al país, indudablemente (Rueda, 2008).

Un apartado singular como "otro actoral" es el que le concedía Kirchner a Duhalde. Si bien no existieron acusaciones o críticas directas hacia la persona del ex gobernador de la provincia de Buenos Aires, sí pueden advertirse a partir de 
la ruptura de la alianza Kirchner-Duhalde en el año 2005, algunas valoraciones negativas a lo que representaba políticamente su figura.

Ahora bien, aunque en los posicionamientos de los dirigentes partidarios no se registran valoraciones negativas hacia Duhalde, sí es posible advertir en la mirada negativa de los sindicalistas una clara definición del ex gobernador de la provincia de Buenos Aires, especialmente de aquellos dirigentes que decían adscribir al MTA o al moyanismo. Éstos consideran que durante su gestión como presidente transitorio llevó medidas desfavorables para los trabajadores como fue la devaluación, y luego, durante el gobierno de Kirchner, se constituyó en uno de los mentores de la salida de sectores sindicales vinculados con Luis Barrionuevo de la CGT tras cuatro largos años de fortalecer la unidad sindical ${ }^{12}$, así como también fue uno de los responsables, junto con Barrionuevo y otros dirigentes como el "Pata" Medina o Gerónimo Venegas, de opacar la jornada de traslado de los restos de Perón a la quinta de San Vicente.

Un segundo grupo de actores considerados como "otros" son los Organismos Multilaterales de Crédito, entre los cuales Kirchner incluía a la Organización Mundial de Comercio (OMC), el Banco Mundial (BM), y particularmente al Fondo Monetario Internacional (FMI). Su mirada negativa sobre estas instituciones se ancla en las iniciativas realizadas en las décadas anteriores que llevaban implícitas una subordinación de la sociedad y la economía al cumplimiento de obligaciones externas, pero también una responsabilidad central en el devenir y desarrollo de la crisis de $2001 .^{13}$

Esta fuerte crítica hacia dichos organismos tuvo una clara resonancia en la cosmovisión de la CGT, evidente por ejemplo en las notas de prensa con fecha $06 / 10 / 06$, donde se señala la necesidad de finalizar con la impronta de las políticas del Consenso de Washington ya que no colaboraron sino a hacer "sufrir en carne propia" lo que se planteaban como "recetas 'salvadoras' del primer mundo" que terminaron produciendo el "remate" de las empresas nacionales y un impacto negativo en la calidad de vida de los argentinos.

Un tercer colectivo de actores a los que le asigna una fuerte negatividad es el de los denominados grupos económicos. La animadversión que el ex gobernador de Santa Cruz manifestó reiteradamente hacia estos sectores era compartida por la conducción de la CGT durante su gobierno, ya que apuntaban que uno de los roles de la organización sindical es justamente enfrentar este tipo de corporaciones empresariales que tienden a querer amedrentar la acción sindical y debilitar los derechos de los trabajadores.

Dentro de estos grupos económicos existen al menos tres acepciones diferenciables que concentran la crítica de Kirchner: primero, los grupos al frente de la privatización de las empresas públicas durante la década del noventa; segundo las Administradoras de Fondos de Jubilaciones y Pensiones (AFJP) que, en palabras de Kirchner, terminaron "vaciando" el sistema de seguridad social; y finalmente, los grupos económicos que forjan los precios de las carnes que buscaban "ganancias fáciles" y que tuvieron una cercanía con el golpe de Estado de $1976 .{ }^{14}$ 
Respecto de este último grupo, para los dirigentes partidarios kirchneristas los grupos económicos vinculados a los productos agrícola-ganaderos carecen de un sentido de la responsabilidad nacional; en tanto que la CGT manifestaba en 31/01/06 en su nota de prensa que la Sociedad Rural Argentina (SRA) posee un afán de enriquecimiento desmedido y fue la que “...cobijó a la oligarquía vacuna y fue cómplice de todas las dictaduras militares que asolaron a nuestro país".

Por último, entre los principales actores que eran observados de forma negativa, según Kirchner, se encuentran los medios de comunicación. Uno de los argumentos principales que esgrimía el presidente era el desconocimiento o mala información de la realidad que poseían los periodistas, pero también su rol cultural, político y económico en épocas recientes de la historia argentina en la cual escribieron "como el viento venía" o "de acuerdo con los intereses que debían representar". ${ }^{15}$

Si se toma en cuenta la valoración de la dirigencia sindical entrevistada al respecto, señalan el desacople entre los hechos y el relato de los medios de comunicación, como, por ejemplo, en lo que respecta a la discusión salarial, pero sobre todo en situaciones particularmente conflictivas como fue la Jornada de San Vicente. ${ }^{16}$

\section{El caso brasileño:}

\section{c) Nosotros actorales:}

Si se analiza cuáles son los actores que discursivamente en Brasil tanto el presidente Lula como los dirigentes partidarios y sindicales reconocieron como parte de su "nosotros", al igual que en el caso de Argentina, es posible diferenciarlos entre aquellos que pertenecen al plano político partidario y al mundo del trabajo.

Un primer actor valorado positivamente por Lula son los Ministros de su gabinete, enfatizando especialmente el pasado sindical de gran parte estos. En coincidencia, los dirigentes del PT que fueron entrevistados reconocieron a los ministros Luis Marinho, Ricardo Berzoíni, Jaques Wagner, Olívio Dutra, entre otros, tanto por su labor como por su experiencia política y sindical. ${ }^{17}$ Estos ministros de vertiente sindical son valorados positivamente también por los sindicalistas entrevistados, quienes extienden dicha estima hacia otros actores del ámbito estatal, como por ejemplo el personal del Ministerio de Trabajo y Empleo y numerosos parlamentarios e intendentes provenientes de raíces sindicales. ${ }^{18}$

Cuando Lula se refería positivamente a los partidos políticos, lo hacía teniendo en cuenta a los socios de su coalición de gobierno en general, y particularmente a los que poseían una vertiente ideológica de izquierda o centro izquierda, como el caso del PSB, PC do B y, por supuesto, el PT.

La mirada de los dirigentes partidarios entrevistados reitera en cierta medida el argumento sostenido por Lula de apreciar a los partidos de la coalición de gobierno, que puede verse claramente en la resolución del PT del 24/03/2003:

$\mathrm{Na}$ montagem do governo define-se uma configuração de centro-esquerda, com clara hegemonia da esquerda, definida pela forte presença do PT e de seus aliados tradicionais. Além dos partidos de esquerda, -PT, PC do B, PV, PMN, PCB, PSB, PDT e PPS- e dos partidos de centro-PTB, PL e setores do PMDB- o governo é marcado por uma mati- 
zação não partidária importante, representada pelos ministros da Agricultura e da Indústria e Comércio (Resoluciones del PT, 24/03/2003).

Si se tienen en cuenta los posicionamientos institucionales de la CUT, ésta hace exclusiva referencia en forma positiva al PT, al PC do B, e incluso al viejo PCB (luego convertido en PPS), lo cual obedecía en parte a que dentro de la CUT estos partidos convivían como las principales referencias partidarias de los afiliados. ${ }^{19}$

En cuanto a los actores que, dentro del mundo del trabajo, lograron una valoración positiva cabe señalar a los trabajadores, que fueron centrales en los discursos de Lula, a los cuales colocó como la principal riqueza de Brasil. ${ }^{20}$ Inclusive, al igual que su par argentino, Lula planteaba que su objetivo era que los trabajadores vuelvan a conquistar la dignidad, es decir que "recuperen la sonrisa".

Desde la mirada de los dirigentes partidarios y las expresiones institucionales del PT, los trabajadores son parte ineludible de su "nosotros" por dos motivos: la génesis de la organización partidaria ${ }^{21}$ y lo que el triunfo electoral de alguien considerado un "trabajador" significó para la clase trabajadora. ${ }^{22}$ En cuanto a los dirigentes sindicales entrevistados, éstos tienen como eje principal de su "nosotros actoral" a los trabajadores, ya que son la razón de ser de su actividad. Ahora bien, son varios los que reconocen que la obtención plena de derechos de los trabajadores estuvo condicionada directamente por su capacidad de incidencia política.

Las referencias positivas que llevó a cabo Lula con relación al sindicalismo fueron numerosas, pero pueden distinguirse claramente dos situaciones: la primera, evocando al sindicalismo en forma general; y la segunda, enfocándose específicamente en la CUT y los gremios de mayor cercanía histórica y política, especialmente los metalúrgicos paulistanos y los vinculados con el trabajo rural en el nordeste.

Particularmente en lo que atañe a la CUT, para Lula ésta era "como su casa", lo cual refería directamente a su rol protagónico en la génesis de la Central y el hecho de que las "luchas" de la Central las consideraba como propias. ${ }^{23} \mathrm{Si}$ en cambio se toma en cuenta la mirada de los dirigentes partidarios con respecto a la CUT, todos reconocen rotundamente la preeminencia de la Central sobre las demás expresiones sindicales a la hora de componer este "nosotros sindical" del Gobierno Lula y del PT, no sólo por el origen compartido del PT y la CUT, sino también porque gran parte de los dirigentes de la Central eran petistas, porque existieron entre el PT y la CUT fuertes elementos programáticos compartidos y porque ambas organizaciones se brindaron apoyo explícito en los momentos electorales. ${ }^{24}$

Cuando se toman en cuenta las opiniones vertidas desde el ámbito sindical, son varios los entrevistados que reconocen que a pesar de la identificación histórica entre la CUT, el PT y Lula, a partir de 2002 la situación cambió drásticamente. El presidente de la CUT, Artur Henrique da Silva (2009), señala que el error que se cometió fue el de creer que el gobierno Lula era "su gobierno", lo que llevó a resentir la finalidad propia del sindicalismo, e incluso colaboró con que los sectores dentro de la CUT que eran opositores a la dirección y al gobierno (como INTERSINDICAL y CONLUTAS) tomaran partido de este desconcierto. Sin em- 
bargo, también manifiestan cómo a partir del año 2005 en el que el proyecto del Gobierno Lula fue puesto en cuestionamiento por los sectores conservadores, la defensa de la continuidad del PT en el Palacio de Planalto resultó una de las decisiones mayoritarias adoptadas por la CUT, como puede verse en los lineamientos del $9^{\circ}$ Congreso Nacional de la CUT en el año 2006:

A direita neoliberal conservou boa parte de seu poder econômico e político, apesar da derrota eleitoral de 2002. A grave crise política iniciada em 2005 teve como motivo aparente a corrupção, mas seu pano de fundo é esta ferrenha luta pelo poder. Os setores conservadores utilizaram as denúncias contra membros do governo e alguns partidos da base governista para avançar suas posições, visando as eleições de 2006. Buscaram, desde o início, desgastar o governo, a autoridade do presidente e o PT, principal partido de sustentação, aguçando irremediavelmente a disputa política (...). É preciso neste momento, organizar o combate contra o retorno do neoliberalismo em nosso país. A direita brasileira vem apresentando, através de seus porta-vozes (FHC, Serra e Alckimin) um programa de retorno à presidência do Brasil, que tem como alguns dos seus pontos centrais: uma reforma trabalhista que retire direitos dos trabalhadores; retomada das privatizações e das negociações com os EUA para a criação da ALCA; privatização de todos os bancos estaduais; adoção da política de déficit nominal zero e a redução das despesas constitucionalmente obrigatórias em áreas como saúde e educação (CUT, 2006).

En el marco de esta disputa frente a los sectores conservadores entre 2005 y 2006, la CUT terminó por definir su rol con el gobierno y el PT, al hacer explícito por primera vez en su historia el apoyo institucional a la fórmula electoral que encabezaba Lula a la presidencia. A partir de la mitad del mandato de Lula en la primera presidencia, la CUT se convierte en el principal baluarte sindical del gobierno y el PT el principal partido de referencia, con lo cual la sinergia identitaria entre la CUT, el Gobierno y el PT adquiere una profundidad e institucionalización mayor.

\section{d) Otros Actorales:}

En lo que atañe a la constitución discursiva del "otro", es posible advertir que, en general, los adversarios políticos de Kirchner y Lula eran prácticamente los mismos en uno y otro contexto. Sin embargo, en los discursos de Lula, uno de los elementos destacados es la ausencia de personalidades que ocuparan el rol de "otros" actorales en el plano político. En general el ex sindicalista colocaba en este lugar a actores colectivos, como, por ejemplo, los gobiernos anteriores, la dirigencia política y partidaria, el congreso y la efigie de los opositores.

Cuando Lula se diferenciaba de los gobiernos anteriores lo hacía en base al siguiente argumento: estos gobiernos no sólo prometieron y no cumplieron, no sólo hicieron lo que no había que hacer, sino que también fueron carentes de coraje 
para llevar adelante las reformas "necesarias", en lo cual resuena en gran medida el diagnóstico realizado por Kirchner para Argentina.

Entre los demás actores emplazados en el discurso de Lula en la figura del "otro", se manifiesta como evidente la ausencia de referencias partidarias directas, aunque a partir de su caracterización de espacios deliberativos como el Congreso puede tomarse en cuenta en qué medida este tipo de actores estuvo presente, aunque de forma velada o implícita. ${ }^{25}$

En este punto la mirada de los dirigentes petistas entrevistados es fuertemente coincidente con la del presidente, ya que consideran unívocamente que el Congreso fue el espacio por excelencia en el que interpusieron su veto los "sectores conservadores" vinculados a los gobiernos anteriores ya los intereses empresariales y corporativos. ${ }^{26}$

Desde la perspectiva de la CUT, la coincidencia de argumentación es notoria, puesto que endilgaban a los gobiernos de Fernando Collor de Mello y Fernando Henrique Cardoso el emplazamiento del neoliberalismo como matriz política, social y económica. ${ }^{27}$ Ahora bien, uno de los aspectos que resulta novedoso, si se tiene en cuenta la mirada de los dirigentes sindicales de la CUT en este punto, fue el reconocimiento de exponentes de la dirigencia política que no sólo se emplazaban en los sectores conservadores o en los gobiernos previos, sino más bien en sectores con una mirada "radical de izquierda" como parte de su "otros actoral". Algunos de estos ejemplos incluyen a quienes se escindieron del PT, como Heloísa Helena, fundadora del PSOL, y Zé María, exponente principal del PST-U. ${ }^{28}$

Si se recuperan nuevamente los demás "otros actorales" de tipo político que identificaba Lula en sus discursos, uno de los aspectos sobresalientes era la constitución de los opositores como un adversario genérico, inaugurado durante el año 2005 cuando inicia el Mensalão.

En la visión del presidente, este "otro" opositor era quien construía una mirada permanentemente negativa sobre todas las acciones de su gobierno, como se evidencia en un discurso presidencial del 19/04/06 referenciado a continuación:

E eu sabia que ia ser difícil, e eles imaginavam que o Brasil fosse quebrar no primeiro ano que eu ganhei as eleições. Até porque eles sabiam que o barco estava cheio de furos, estava entrando água por tudo quanto é lado, e eles falaram: "esse governo não vai conseguir tapar esses buracos, daqui a um ano nós vamos culpá-los e, depois, nós voltamos" (Discurso de Lula, 19/04/06).

Cuando se recupera la perspectiva de los dirigentes partidarios en este punto, la figura de los "opositores" adquiere la caracterización de elite política, de carácter conservadora, con una orientación ideológica de derecha, con un enraizamiento secular en los lugares privilegiados de poder, y con una orientación política contraria a cualquier tipo de movimientos y expresiones sociales y populares.$^{29}$ Inclusive, si en el discurso de Lula este "otro actoral" carecía de referentes explícitos, para los petistas sí es posible identificar claramente al PFL, el PSDB ${ }^{30}$, el PSOL y el PST-U ${ }^{31}$ como sus antagonistas. 
La mirada sindical en este punto es similar al que llevan a cabo los petistas, tal como se expresa en el siguiente fragmento de la entrevista al otrora presidente de la CUT a nivel nacional Artur Henrique da Silva:

Quando se percebe que direita, direita entendendo os democratas, que era o PFL na época, junto com os tucanos do PSDB, parte da mídia e parte da elite empresarial financeira, começam uma grande campanha pelo impeachment do Lula, para derrubar o governo Lula, mesmo com todos os problemas ocorridos dentro do PT e dentro da disputa do Mensalão, houve um olhar, uma descoberta para aquilo que estava acontecendo no país. Quer dizer, havia uma preocupação por parte da direita e da elite daquilo que o governo começava a fazer, mesmo com a questão da previdência (Henrique Da Silva, 2009).

La conformación de los adversarios en el discurso de Lula, al igual que en el del PT y la CUT, tuvo en los medios de comunicación un nuevo antagonista. Lula consideraba que de manera sistemática durante su gestión los medios fueron los que intentaron "vender una idea" sobre el devenir de su gobierno, en general creada desde São Paulo, con la intensión de extrapolarla al resto del país. ${ }^{32} \mathrm{Al}$ igual que Kirchner, resaltaba el accionar político de los medios en su férrea defensa del mercado, en su ataque a cualquier tipo de intervención del Estado en la economía, en la "colonización" de la sociedad para que pensaran que lo que venía de afuera era mejor, entre otros aspectos.

Para los dirigentes del PT que fueron entrevistados, los grandes medios de comunicación brasileños eran considerados como fuerzas conservadoras que trazaron alianza con los sectores de la oposición para llevar adelante un embate constante contra el Gobierno de Lula y el PT durante la crisis del Mensalão en 2005. Aunque esta posición puede verse reflejada en el siguiente fragmento de la resolución partidaria con fecha 19/09/2005, claramente no puede obviarse el devenir judicial posterior del Mensalão, y comprender que este tipo de miradas esconde un intento de los dirigentes de expiar o proyectar hacia fuera las culpas y problemas de corrupción que cargaban hacia su interior:

Ao longo dos últimos meses, um conjunto de denúncias contra o PT e o governo Lula foram divulgadas, todos os dias, pelos meios de comunicação do país, investigadas por três CPIs no Congresso, pela Polícia Federal, Ministério Público, e por outros organismos em diversos estados e municípios. Nunca na história do regime democrático brasileiro um partido sofreu tamanha inquirição, duros e sistemáticos ataques de partidos oposicionistas, divulgados com a ajuda irrestrita da ampla maioria da mídia" (Resolución del PT, 19/09/2005).

Como pudo advertirse previamente, en la cosmovisión de la CUT y sus dirigentes, los medios de comunicación son considerados como un "otro", no sólo por su posicionamiento en el embate frente a Lula y su gobierno, sino también por el carácter monopólico y su capacidad de imponer una visión particular del mundo. ${ }^{33}$ 
Inclusive, esta problematización sobre los medios se puso de manifiesto en el $9^{\circ}$ Congreso Nacional de la CUT en el año 2006 cuando se planteó que el control de la "gran prensa" y la apertura de nuevos espacios alternativos era una labor central para la debida "democratización del país". ${ }^{34}$

Entre los actores que dentro del mundo del trabajo adquirieron una connotación negativa en la mirada del presidente Lula se identifican dos referentes: las empresas y bancos privados por un lado, y al "viejo" sindicalismo por el otro. La crítica hacia los primeros radicaba principalmente en que éstos colocaban el beneficio propio en detrimento de la generación de empleos genuinos, el mejoramiento de las condiciones de vida y desarrollo de los trabajadores brasileños ${ }^{35}$; en cuanto a los segundos, la detracción se focalizaba en su baja representatividad sindical y su defensa de la estructura sindical precedente. ${ }^{36}$

En relación con las empresas y bancos privados es interesante destacar cómo, para los dirigentes petistas entrevistados, aquellos eran identificados como el "capital", dando clara muestra de una herencia discursiva de tipo socialista. ${ }^{37}$ Ahora bien, si se toma en cuenta la perspectiva petista respecto de la crítica hacia un sector particular del sindicalismo brasileño, la coincidencia con Lula es total, puesto que en reiteradas ocasiones se evoca la génesis del PT en combate contra el sindicalismo "pelego", pero también en referencia al "sindicalismo de resultados" que se desarrolló fuertemente en la década de $1990 .{ }^{38}$

Cuando se observa la posición de los entrevistados sindicales en relación con las empresas y bancos privados, la principal crítica se dirige a las empresas privatizadas en la década de 1990, las multinacionales y los responsables por las altas tasas de interés, ya que fueron ellos los impulsores del modelo neoliberal, con el cual se desestructuró el mercado de trabajo, se debilitó el rol del Estado, generando así el aumento de las desigualdades sociales, la precarización laboral y el desempleo. ${ }^{39}$

Si se toma en cuenta la caracterización en tanto "otro" de actores pertenecientes al plano sindical, la cosmovisión de la CUT y sus dirigentes se torna en este punto más extensa y precisa que las de Lula y el PT, aunque no necesariamente diferentes. Esquemáticamente, pueden reconocerse al menos tres "otros actorales" de tipo sindical en la mirada de la CUT y sus dirigentes. El primero de ellos estuvo directamente relacionado con las principales organizaciones sindicales que actuaban en Brasil, fundamentalmente en referencia a la Força Sindical (FS) en tanto "sindicalismo de resultados" que durante la década de 1990 le anexó un componente "neoliberal" a su práctica sindical. ${ }^{40}$

Un segundo adversario para los dirigentes de la CUT fue el sindicalismo "corporativo", que defendía la cultura sindical del monopolio de la representación, la unicidad y el impuesto sindical. Para exponentes de la directiva nacional de la CUT, como José López Feijóo; estos tres elementos son las bases del "sindicalismo pelego" contra el cual se formó la CUT.

En directa relación con lo anterior, no es menor que muchos de los dirigentes entrevistados de la CUT colocasen como tercer adversario sindical a aquellos sectores que, originalmente, pertenecían a la Central como era el caso de los sindi- 
calistas afines al PC do B, del PST-U o cercanos al PSOL, y luego se escindieron para conformar la CTB, INTERSINDICAL y CONLUTAS, respectivamente. ${ }^{41}$

\section{Reflexiones Finales}

La construcción de identidades es claramente un proceso de múltiples puntos de partidas y de finalización, en el que se entrecruzan diversas líneas de acción tendientes a destruir, reconstruir o bien forjar la identidad misma. En este sentido, la posibilidad de observar el proceso de diferenciación respecto del "otro" y afirmación en un "nosotros" claramente ha tenido una trayectoria y contenido similares como también diferentes en el caso brasileño y argentino.

En el caso argentino, entre el presidente Kirchner, los dirigentes partidarios y sindicales la convergencia discursiva se da en múltiples aspectos. En lo concerniente a los "nosotros actorales", la sinergia entre unos y otros se produce al momento de valorar principalmente la incidencia del peronismo de la provincia de Buenos Aires, destacar la centralidad de los trabajadores, y poner en valor al sindicalismo en general y al liderazgo de Hugo Moyano en particular.

Si se tiene en cuenta la constitución del "otro" en el caso argentino, el ex presidente Kirchner coincide con los dirigentes sindicales y partidarios en el encono hacia Menem como el principal antagonista político, hacia el FMI como principal actor de tipo internacional y, en menor medida, hacia los medios, y, además, se produce una total convergencia de cosmovisiones respecto de los grupos económicos (empresas privatizadas, sectores vinculados a la agro-ganadería y las AFJP).

Si se toman en cuenta las construcciones discursivas de los "otros actorales", uno de los principales aspectos a destacar es que frente a la identificación de Duhalde como un antagonista en los discursos de Kirchner, tanto dentro de la CGT como de la dirigencia peronista existen posiciones divididas al respecto, lo que da clara muestra de la disputa entre Kirchner y el ex gobernador de Buenos Aires hacia el interior de las fuerzas justicialistas y sindicalistas.

En este sentido, puede advertirse que en el análisis de la construcción del "nosotros-otros" en sus múltiples niveles, como un aspecto con el cual dar cuenta de la construcción de identidades partidario-sindicales, claramente en Argentina la negatividad, es decir el reconocimiento del antagonista, es uno de los principales sustratos a partir del cual se da este proceso identitario en el período 2003-2007. Ello se ve reforzado, aunque en menor medida, por la centralidad que ocupan los trabajadores en mayor medida y los sindicalistas en menor, en lo que es la reconstrucción de esta identidad partidario sindical que fundara las bases del peronismo argentino.

En contrapartida al caso argentino, en el que la diferenciación en la figura del "otro" es el principal punto de encuentro entre la mirada presidencial, partidaria y sindical, en el caso de Brasil, la convergencia de opiniones durante el período 2003-2006 es claramente extendida tanto en la configuración del antagonista, como también en la delimitación del "nosotros".

Si se observa la constitución tanto del "nosotros" como del "otros", en el caso brasileño, se puede señalar que son extremadamente pocas las situaciones de di- 
vergencia de opiniones. Ahora bien, es una constante a lo largo de toda la construcción identitaria -especialmente al momento de modelar el "otros"- que el discurso de Lula tenga una impronta de menor radicalidad y especificidad que la que ofrecen tanto los petistas como cutistas. Esto puede observarse claramente en el caso de la diferenciación respecto de los "opositores", la incidencia de los medios, de las empresas y bancos, del sindicalismo (de resultados, corporativo y radical de izquierda), entre otros aspectos.

Más allá de estos señalamientos, es claramente llamativo el nivel de sinergia y sintonía discursiva entre el PT y la CUT, ya que en su mayoría comparten una mirada que no sólo reconoce los mismos elementos a la hora de configurar su "nosotros", sino también una intensidad similar al delinear su "otros", dando una muestra clara de fuerte sintonía identitaria.

Esto permite afirmar que, a diferencia de la convergencia identitaria en la negación, en el antagonista, en el "otros" que se daba principalmente en el caso argentino, la identidad partidario sindical en el caso de Brasil posee un fuerte contenido que pone en evidencia una sólida construcción identitaria entre el PT, la CUT y Lula, al menos en lo que al periodo 2003-2006 respecta.

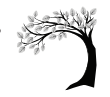

\section{Referencias}

1. El total de casos efectivos sería el Perú de Alan García (APRA), la Argentina de Kirchner (PJ), el Brasil de Lula (PT), el Chile de Michelle Bachelet (PS) y el Uruguay de Tabaré Vázquez (FA).

2. Discurso de Kirchner del 08/08/05: "Cada uno tenemos una verdad relativa y la verdad relativa de uno con la verdad relativa del otro nos da la verdad superadora que nos permite dar las respuestas que necesita nuestro pueblo. Por eso yo les abro mi corazón y mis brazos a los radicales, peronistas, socialistas, independientes, organizaciones sociales, sindicatos, con toda mi fuerza, para trabajar y lograr en San Nicolás el país que queremos".

3. Entrevista a Marcelo López Arias: "Durante la gestión K, en el Senado el kirchnerismo era minoría: el grueso éramos dirigentes peronistas que mirábamos con mayor o menor simpatía a Kirchner pero que considerábamos que había que apoyarlo, más allá de que no fuéramos de su 'ala"'.

4. Entrevista a Ernesto Ríos: "Kirchner llega con la decisión política de que al peronismo hay que matarlo. Clarísimo. ¿Qué se da cuenta después? ...que sin los intendentes de conurbano, que traen movilización y estructura, sin los sindicatos que son los grupos organizados y con capacidad de movilización genuina (...). Los intendentes del conurbano que movilizan y tienen votos, y los sindicatos que tienen capacidad de movilización, estructura y demás guita para la campaña, sin eso no se puede ganar".

5. Entrevista a Marcelo López Arias: "El movimiento obrero siempre fue una parte esencial del peronismo: la relación siempre fue fluida y permanente, más allá de las diferencias que pueden plantearse entre algunos sectores políticos o sindicales".

6. Discurso de Kirchner del 25/08/06: "Por eso les agradezco profundamente a la Confederación General del Trabajo, a sus distintos gremios, al querido amigo Hugo, con quien nos conocemos de tantos años y que compartimos momentos y cuestiones muy difíciles".

7. Entrevista a Claudia Bernazza: "A medida que se fue recuperando la actividad laboral, la industrial sobretodo en el sentido más clásico, recuperando los institutos laborales, organizando las paritarias, las organizaciones sindicales fueron recuperando poderío tanto económico como político. Ese poderío los hace [a los sindicatos] tener cada vez mayor incidencia, tanto en lo que es la conformación de listas como al proyecto político".

8. Entrevista a Alejandro Rossi: "En general, el kirchnerismo deja de pensar la política con toda la ambición con que la pensó en el 2003, pero va a tratar de darle coherencia, no se sienta con los gordos, digamos, abandona el CTA pero no se va a los gordos. Estos jamás han tenido en todos los años del 
kirchnerismo una presencia en una relación política, porque fueron por antonomasia los protagonistas de los 90: Cavalieri, Lezcano, Rodríguez, Triaca".

9. Entrevista a Agustín Rossi: "Cuando asume Kirchner en el gobierno, lo que hay es un corrimiento, una alineación que se va haciendo cada vez más automática de Moyano con el kirchnerismo, que le permite también a Moyano terminar hegemonizando gran parte del Movimiento Obrero detrás de la CGT".

10. Entrevista a Susana Rueda: "El peronismo siempre tuvo una virtud en el gobierno que es: pasada la elección, el que ganó conduce. El que perdió, acompaña. Acompaña y los que eran perdedores se transformaron automáticamente en los mayores ganadores".

11. Discurso de Kirchner del 29/07/05: "Porque muchos de los que hoy hablan fueron los que aplicaron indiscriminadamente las recetas del Fondo sin importarles lo que le pasaba al pueblo argentino (...) Yo digo: desendeudémonos, adiós al Fondo y arriba la patria, que es lo que nosotros necesitamos hoy."

12. Entrevista a Horacio Arreceygor: "Creo que Moyano logra retener a la gran mayoría del movimiento obrero, y hubo una pequeña escisión que fue la de Barrionuevo, que dice que él va a ser el MTA del gobierno de Kirchner. Cuando uno se acuerda lo que era Barrionuevo en el gobierno de Menem apoyando todos los despidos, las privatizaciones..."

13. Discurso de Kirchner del 27/06/03: "Le dije, obviamente con absoluto respeto, que mientras levantábamos la voz, habían otros que nos paseaban a algún presidente por todo el mundo diciendo que había sido el mejor presidente que teníamos los argentinos y que en verdad el modelo económico que se había llevado adelante era un verdadero ejemplo; a los tres años el país saltaba por los aires. Y esos que lo paseaban eran ni más ni menos que los representantes del Fondo Monetario Internacional".

14. Discurso de Kirchner del 30/03/06: "Nosotros nos acordamos de lo que hicieron muchas entidades del campo, que hoy hablan de la libertad. En el año 1976, cuando venía el golpe lo apoyaron decididamente, recordémoslo. Y cuando vino la salida política, hubo un gran comunicado de la Sociedad Rural Argentina que decía: 'no hay que apresurar la salida democrática'. Tenemos recuerdos, la democracia es el bolsillo de ellos, nada más que para los intereses de ellos y los intereses que sirven".

15. Discurso de Kirchner del 25/02/05: "Mucha gente, el pueblo argentino en la calle ni hablar, pensadores, intelectuales nacionales también, pero editorialistas de diarios, de diarios importantes en la Argentina que acompañaron también en su momento, por supuesto, procesos nefastos en este país, decían que cómo los argentinos no honrábamos nuestra deuda, cómo éramos tan maleducados. No levantaban la vista, no veían más allá, la exclusión social, el empobrecimiento de nuestros sectores medios, el quiebre de la estructura productiva, la pérdida global, total del país, el desguace global que sufrió esta Argentina".

16. Nota de prensa de la CGT del 30/10/05: "En razón de la insistencia de algunos medios en hacer aparecer a la C.G.T. de la R A como suscribiendo un acuerdo con la U. I. A. y en virtud de que se trata de fantasías que pretenden convertirse en realidad".

17. Entrevista a José Genoíno: "Alguns companheiros foram bem sucedidos, eu acho que o Lula, nem se fala, o Marinho, alguns companheiros do setor das estatais foram deputados, senadores, governadores, mas nem todos porque a política ela envolve uma elaboração, uma visão mais estratégica, mais sofisticada que as vezes tem dificuldades. Acho que daquele sindicalista combativo, nós temos o Lula principalmente, o Marinho, o Gushiken, que teve um papel importante, o Berzoini que vem do movimento sindical, foi presidente do partido, o Jaques Wagner que é governador e veio do movimento sindical, Olívio Dutra que foi ministro, governador, veio do movimento sindical".

18. $10^{\circ}$ Plenaria de la CUT realizada en 2002: "Na relação da CUT com o Legislativo federal, estadual e municipal, devemos formular emendas constitucionais em conjunto com parlamentares, deputados e senadores comprometidos com a classe trabalhadora, para efetivar o papel do Estado e das políticas públicas que defendemos, como também intervir na construção das leis orgânicas dos municípios".

19. Entrevista a Arthur Henrique da Silva: "Quando vem a eleição de 1989, Lula e Collor, o PCdoB toma a decisão no alto comando do partido de fazer aliança com o PT, aliança preferencial do PCdoB naquele momento histórico até hoje com o PT (...). Ao tomar essa decisão o partido, o partido orienta o seu sindicato e ai é uma relação de correia de transmissão, é direto, então é, eu digo orienta para ser educado, mas na verdade manda. Então, encaminha aos seus sindicatos a seguinte orientação: o 
Lula vai ganhar a eleição do Collor, nós precisamos estar juntos no governo e o Lula vai precisar ter uma base social cada vez mais ampla para poder governar, por tanto, a base do PCdoB, dos nossos sindicatos deve vir para a CUT, que será essa base sindical do governo Lula. E ele entra em 1989, e os sindicatos vem para dentro da CUT em 1991, oficialmente o PCdoB vem para a CUT, todo ele, em 1991, num acordo conosco dizendo o seguinte: não vamos abrir mão de defender unicidade, imposto sindical, mesmo sabendo que a CUT no seu estatuto é contra, mas nós queremos vir para dentro da CUT, como a CUT é central única, pelo menos no nome, em tese nós teremos que aceitar todas as correntes de pensamento...".

20. Discurso de Lula del 30/04/06: "O Brasil será ainda mais vitorioso no dia em que estas conquistas beneficiarem a todos os brasileiros. Estamos lutando fortemente para isso. E graças a Deus e a muito trabalho temos conseguido bons resultados. Ao contrário do que se dizia, estamos provando que distribuição de renda faz o país crescer (...). Cada vez mais me convenço que a nossa principal riqueza é o trabalhador. E quando falo trabalhador, falo de todos os brasileiros e brasileiros que nas mais diferentes profissões constroem a riqueza desta nação".

21. Entrevista a Tácito Pereira dos Santos: "O PT não surge de uma classe de iluminados, de intelectuais ou de uma pseudo-cúpula, ele nasce da base, da necessidade de organização da classe trabalhadora, da luta dos trabalhadores com o fim da ditadura militar. Nesse sentido são várias as matizes de formação do PT: sindical, religioso, popular, intelectual e de militantes da esquerda tradicional que lutaram contra a repressão militar".

22. Resolución del PT del 10/02/07: "As mudanças que introduzirá em nossa sociedade e no sistema político não podem ser apenas um hiato progressista em uma história conservadora, mas o desencadeamento de um longo ciclo de transformações iniciado pelo mandato presidencial de um trabalhador, pelo PT e por uma coligação de partidos de esquerda e seus aliados democráticos".

23. Discurso de Lula del 04/06/03: "Eu quero dizer para vocês que, cada vez que eu participava de um Congresso da CUT, era como se eu estivesse na minha casa, conversando com a minha mulher e com os meus filhos, porque, no meio de companheiros, eu me sinto como se estivesse em casa. E mesmo aqueles que possam divergir, nós temos que respeitá-los, porque na casa da gente também, muitas vezes, a família pensa diferente. Entretanto, nós temos que levar em conta o que nós queremos, o que estamos fazendo para que a gente possa ter a dimensão do passo que cada um de nós pode dar".

24. Entrevista a Gleissy Hoffman: "a CUT é uma central única quase que majoritariamente petista, a maioria dos dirigentes da CUT são ligados ao PT, tem muitas questões programáticas que a gente defende junto". Entrevista a Rui Falcão: "Boa parte dos dirigentes da CUT são também militantes do PT (...) então muito embora na própria concepção do PT e no surgimento da CUT, a questão da autonomia, diferença de instâncias, da forma de atuação, elas sejam distintas no reconhecimento formal, mas há uma imbrincação, e há muitas vezes uma dinâmica quase comum das duas entidades, partido e sindicato, há uma certa confusão, como muitas vezes ocorreu também uma confusão entre partido e governo em alguns momentos da vida do PT".

25. Discurso de Lula del 21/05/06: "Esse Fórum Nacional já produziu uma proposta de reforma sindical, está no Congresso Nacional, ainda tem algumas divergências. As divergências serão dirimidas dentro do Congresso Nacional, na convergência dos dirigentes sindicais com os deputados, para ver qual é o tipo de estrutura sindical que a gente precisa. Possivelmente, ela não atenda os interesses de $100 \%$ dos que estão participando do movimento sindical mas, também, só Cristo pode ter unanimidade. Mesmo assim, na Santa Ceia ele não teve, porque teve um traidor lá".

26. Entrevista a Marco Martins: "Então, nós temos que ajudar de alguma forma, que tenha êxito no governo, no mandato, porque nós já temos diversos adversários, principalmente a elite que permanentemente vive bombardeando, querendo arrancar recursos para resolver problemas deles. Se a gente também sai fazendo o mesmo, vamos massacrar nosso governo. A gente sabe que se ganhou o governo, mas não se ganhou o poder".

27. $10^{\circ}$ Plenária Nacional de la CUT realizada em el 2002: “...O neoliberalismo de FHC trouxe como resultado a diminuição de renda dos trabalhadores, o desemprego, as privatizações com desnacionalização, o aumento da dívida e um crescimento medíocre. A concentração da renda aumentou e hoje disputamos a lanterna dos indicadores sociais. Mas há uma realização ligada à imagem de FHC, que já 
nos derrotou duas vezes: a estabilidade da moeda -que foi a principal realização da política econômica inspirada no receituário do FMI. A população gostou da queda da inflação e teme sua volta. Aconteceu o mesmo em toda a América Latina e outras regiões do mundo".

28. Entrevista a Artur Henrique da Silva: “... havia dentro da CUT uma figura, que é o Zé Maria, que era um dirigente da CUT, a pesar de ser do PSTU, e ele se lançou como candidato a presidente da república pelo PSTU, que não tinha base social, muito pouco voto, fazia um discurso bem radical de esquerda, mas ele estava dentro da CUT. E quando a gente na disputa política tomou posição por apoiar ou indicar o apoio de sua base a um projeto democrático popular, ao projeto do Lula, porque comparativamente com Fernando Henrique Cardoso, do ponto de vista dos trabalhadores é melhor você ter um governo democrático popular. Venceu essa tese dentro do congresso, o Zé Maria saiu depois da CUT montou depois seu partido (...). E o PSOL, que é o pessoal que saiu do PT, principalmente capitaneado pela Heloisa Helena e pelo Ivan Valente aqui em São Paulo, saíram do PT no auge da crise, pularam do barco, e criaram a Intersindical, que está numa crise de identidade, porque tem uma parte que acha que foi um erro sair da CUT e outra que acha que temos que fundir com o PSTU e CONLUTAS, para tentar dar mais força a essa chamada esquerda revolucionária".

29. Resolución del PT del 19/09/05: "Quando Lula chegou ao governo, o país estava quebrado e a expectativa da direita neoliberal era que Lula, no governo, levasse o país ao desastre, o que geraria o isolamento interno e externo do país. Esse foi o primeiro desafio que o governo Lula enfrentou".

30. Resolución del PT del 10/12/05: "Mas não enxergamos qualquer tipo de autoridade ou sinceridade nas críticas vindas do PSDB e do PFL. Nunca é demais lembrar: foram estes partidos que capitanearam, durante os oito anos de governo FHC, a entrega na bacia das almas de nossas empresas estatais, a multiplicação por dez da dívida pública, uma abertura comercial que serviu a interesses alienígenas, a destruição de parte de nosso parque produtivo, a redução criminosa do Estado brasileiro, a criminalização dos movimentos sociais".

31. Entrevista Rui Falcão: "Mesmo o projeto do PSOL ou do PSTU acabaram se conformando como partidos de pouca expressão política nacional, com impacto mais de representação parlamentar. Não tem uma grande influência no movimento sindical, na vida concreta da sociedade, dos governos".

32. Discurso de Lula del 29/11/04: "Eu acompanhei a imprensa, Genoíno, e vou passar um detalhe para vocês. Eu vi uma matéria assim: 'O PT perdeu a classe média'. E eu fiquei pensando: que classe média 'cara pálida'? Vai lá dizer para o Pimentel que nós perdemos a classe média. Vá dizer para o Déda que nós perdemos a classe média. Vá dizer para Luizianne que nós perdemos a classe média. Vá dizer para todos os prefeitos eleitos da capital e do interior que nós perdemos a classe média (...). Então, tentam pegar uma circunstância para tentar vender a idéia: 'o PT perdeu'. O PT nem perdeu, e nem o PT e o PSDB foram protagonistas desse processo eleitoral, porque principalmente a partir da imprensa de São Paulo se vende a idéia que houve um confronto nacional entre PT e PSDB, e que um ganhou e o outro perdeu".

33. Entrevista a João Batista Lemos: "O problema ai é colocado de uma forma assim, há uma ofensiva midiática muito grande, a grande mídia que é controlada pelas transnacionais da comunicação, que monopoliza a comunicação também fez uma trabalho muito grande para desgastar o governo Lula, isso a grande imprensa, os canais de televisão aproveitaram as contradições do governo Lula para tentar desgastar o governo Lula, até ameaçar com o impeachment".

34. $9^{\circ}$ Congreso Nacional de la CUT realizado en el año 2006: “...que a CUT mobilize os trabalhadores e a sociedade civil na luta pelo controle social dos meios de comunicação de massa, para monitorar e dar visibilidade à estrutura e ao modo de atuação das redes de televisão e rádio, bem como à influência do capital estrangeiro sobre elas, formulando proposições que combatam a concentração e os conglomerados de mídia; A resolução do $8^{\circ}$ CONCUT apresentou, de modo correto, a comunicação como um 'setor estratégico para a devida democratização do país'. Diariamente nos defrontamos com veículos de comunicação comerciais, ou a chamada grande imprensa, oferecendo suas páginas para ataques contra o pensamento de esquerda, contra as atividades da CUT, do Movimento Sem-Terra -MST-e de outras entidades de luta e seus dirigentes (...). Ao longo do tempo, forma-se na população conceitos baseados em um pensamento único e predominante. Um projeto de comunicação da CUT que pretenda se tornar uma das frentes de resistência ao massacre ideológico dos meios de comuni- 
cação do capital, deve buscar todas as possibilidades de intervenção nesses veículos, mas, prioritariamente, criar uma rede de comunicação própria, que possibilite a disseminação de conceitos raramente expressos na grande imprensa".

35. Discurso de Lula del 20/10/04: "Quero dizer a vocês que já estive do outro lado, muitas vezes reivindicando do governo medidas de ordem econômica, para esvaziar os pátios das empresas que ameaçavam, muitas vezes, mandar dezenas de trabalhadores embora (...). Quero dizer aos empresários da indústria automobilística, aos empresários da indústria de autopeças, que já vi empresas enormes serem transformadas em, praticamente, um salão de importação de autopeças de países mais ricos do que nós porque, um belo dia, se resolveu que era preciso acabar com a indústria de autopeças no Brasil".

36. Discurso de Lula del 10/04/03: "Porque, vamos ser francos, tanto do lado dos trabalhadores, como do lado dos empresários, tem muito sindicato de carimbo. Vamos ser francos, a maioria dos empresários não se sente representada pelos seus sindicatos e, agora, com as grandes corporações, depois do processo de privatização, é que perderam a representatividade".

37. Resolución del PT del 03/02/2006: "A oposição, capitaneada pela aliança tucano-pefelista que governou o Brasil por oito anos, desempregando, privatizando e desestruturando o Estado Nacional e submetendo o país aos interesses do capital financeiro internacional, precisa desesperadamente desconstruir a imagem de nosso governo e, por isso, acirrará seus ataques no próximo período. Mobilizar pela reeleição de Lula é lutar contra o retrocesso em relação à privatização e a desregulamentação típicas da aliança tucano-pefelista".

38. Entrevista a Luci Chonacky: "O PT nasce nesse meio, o berço do PT foi o sindicato, a luta pela terra, onde depois vai se ampliando nesse sentido, é o berço, o PT hoje negando os sindicatos combativos, não os pelegos, porque o PT nasceu se contrapondo aos pelegos, aqueles que apoiavam a ditadura militar, que estavam do lado dos patrões e não dos trabalhadores". Entrevista a Gleissy Hoffman: "tem dois setores políticos da sociedade brasileira que tem uma identificação sindical maior, é um seguimento capitaneado pelo PT, ai o PT ficou muita força nisso, ligados aos sindicatos dos trabalhadores, movimento sindical trabalhista, trabalhadores rurais, enfim, então isso é forte. E por um outro lado, mais capitaneado pelos Democratas e PSDB, uma ligação com o movimento sindical patronal, federações de indústria, de comércio, enfim, em relação aos interesses e das formas de luta que esses partidos travam, seja no parlamento, ou mesmo quando são governo, quando são executivo".

39. $8^{\circ}$ Congreso Nacional de la CUT en 2003: "O governo Lula, como indicam os primeiros meses de mandato, será alvo de intensas pressões, ameaças e chantagens. As elites neoliberais, fragorosamente derrotadas nas urnas, farão de tudo para manter a orientação macroeconômica que serve unicamente aos interesses da oligarquia financeira. Elas tentarão enquadrar o novo governo, vendendo a falsa idéia de que não há alternativas às imposições do deus mercado".

40. $10^{\circ}$ Plenaria Nacional de la CUT realizada en 2002: "O governo FHC vem implementando, com o apoio da Força Sindical, uma reforma trabalhista e sindical neoliberal, que é o principal obstáculo à liberdade sindical (...). O sindicalismo de resultados, e sua evolução para um sindicalismo neoliberal, estabeleceu um novo patamar para essa disputa de projetos. Desde 1986/1987 as classes dominantes contam com o suporte de um setor do movimento sindical que, nos anos 1990, tem apoiado a implementação do projeto neoliberal. Trata-se de um sindicalismo subordinado ao horizonte político e ideológico da burguesia. A novidade é que essa disputa não ocorre mais apenas de forma localizada, nas eleições sindicais, ou na diferenciação de posições políticas perante o governo federal e suas iniciativas. Nos últimos anos há um claro esforço da Força Sindical, expressão maior do sindicalismo neoliberal, de ampliar sua legitimidade social e sua representatividade. Isso tem sido feito em dois âmbitos".

41. Entrevista a Valter Sanchez: "Os primeiros que saíram foram os ligados ao PSTU, que tinham uma perspectiva muito diferente, sempre tiveram a sua atuação orientada puramente ao partido, nunca foi uma orientação da central, nunca se submeteram, depois teve saída de gente do PSOL, e mais recentemente do pessoal do $\mathrm{PCdoB}$. Todos por orientação de se submeter mais à orientação do próprio partido do que da central. A CUT sempre teve uma atuação onde o PT nunca mandou na CUT, mas nos casos dessas outras centrais estão muito mais identificadas com os partidos". 


\section{Bibliografía}

G. ABOY CARLÉS (2006), "Repositionnement et distance du populisme dans le discours de Néstor Kirchner", en A. CORTEN (editor), Les frontères du politique en Amérique Latine. Imaginaires et émancipation, Paris, Éditions Karthala.

O. AMARAL (2009), As transformações na organização interna do partido dos trabalhadores entre 1995 e 2009, Tese apresentada ao Programa de PósGraduação em Ciência Política da Universidade Estadual de Campinas (Unicamp) para a obtenção do título de Doutor em Ciência Política. Disponible en versión digital en: $<$ http://opiniaopublica.ufmg.br/site/files/biblioteca/Tese-Final-OswaldoAmaral.pdf $>$ O. AMARAL (2011), "Ainda conectado: o PT e seus vínculos com a sociedade", en Opin. Publica, Vol. 17, $\mathrm{N}^{\circ}$ 1. Disponible en versión digital en: <http://www.scielo.br/scielo.php?script=sci_ arttext\&pid=S0104-62762011000100001\&lng=en\&nrm=isoZ $>$

E. IGLESIAS y J. B. LUCCA (2016), "Decisiones teórico-metodológicas para el estudio de las interacciones entre partidos políticos y organizaciones sindicales”, en E. IGLESIAS; V. VENTICINQUE; J. B. LUCCA y M. N. FERRI (Comps.), Partidos políticos y sindicatos en Rosario, Rosario, UNR Editora.

H. KRAAY (2007), "Introduction: Negotiating Identities in Modern Latin America", en H. KRAAY (ed.), Negotiating identities in modern Latin America, Calgary, University of Calgary Press.

S. LEVITSKY y S. MAINWARING (2007), "Movimiento obrero organizado y democracia en América Latina”, en Revista Post Data, No 12, Buenos Aires, Grupo Interuniversitario Post Data Ediciones.

S. LEVITZKY (2005), La transformación del justicialismo. Del partido sindical al partido clientelista. 1983-1999, Buenos Aires, Siglo XXI Editores.

J. B. LUCCA (2011), "Origem e transformação do enraizamento sindical do Partido Justicialista (Argentina) e do Partido dos Trabalhadores (Brasil)", em Revista Brasileira de Ciência Política, № 5, Brasilia. Disponible en versión digital en: <http://www.rbcp.unb.br/artigos/rbcp-n5-80.pdf $>$.

J. B. LUCCA (2012), "El vínculo partido-sindicato en el Brasil de Lula y la Argentina de Kirchner", en International Journal of Latin American Studies, Año 2, Vol. 2, № 1, Korea.

J. B. LUCCA (2013), "Política y sindicalismo durante el primer gobierno de Lula da Silva en Brasil", en A. FERNÁNDEZ (Comp.), Rasgos y perpectivas de la nueva izquierda en América del Sur. Partido politicos y Movimientos sociales, Rosario, Editorial Homo Sapiens.

J. B. LUCCA (2014), "Conflictos y realineamientos de los actores sociales y políticos durante el gobierno de Néstor Kirchner”, en Sudamérica: Revista de Ciencias Sociales, Nㅜ 3, Mar del Plata, Universidad Nacional de Mar del Plata. Disponible en versión digital: $<$ http://fh.mdp.edu.ar/revistas/index. $\mathrm{php} /$ sudamerica/article/view/1049>.

J. B. LUCCA, G. BENETTI y E. IGLESIAS (2017), "Partidos, Sindicatos y los Gobiernos del diálogo social en Argentina, Brasil y Uruguay en el siglo XXI", en M. CAVAROZZI et al. (Comp.), Itinerarios políticos contemporáneos en Argentina, Brasil, Chile y Uruguay, Rosario, UNR Editora (en prensa).

M. V. MURILLO (2005), Sindicalismo, coaliciones partidarias y reformas de mercado en América latina, Madrid, Siglo XXI Editores.

R. RADERMACHER y W. MELLEIRO (2007), “El sindicalismo bajo el gobierno de Lula”, en Revista Nueva Sociedad, No 211, FES, Venezuela.

D. RODRIGUEZ (2014), "Populismo y liderazgo en la democracia Argentina: Un cruce comparativo entre el menemismo y el kirchnerismo", Postdata, Vol 2, № 19, Buenos Aires. Disponible en versión digital en: <http://www.scielo.org.ar/scielo.php?script=sci_arttext\&pid=S1851-96012014000200011$\& \operatorname{lng}=$ es\&nrm=iso>.

T. SKOCPOL y M. SOMMERS (1994), "The Uses of Comparative History in Macro Social Inquiry", en Social Revolutions in the Third World, Cambridge, Cambridge University Press.

C. TILLY (2005), Identities, Boundaries and Social Ties, Boulder and London, Paradigm Publishers.

\section{Documentos sindicales y partidarios:}

CTB (2010), Principios e Objetivos da CTB. Disponible en versión digital en: <http://portalctb.org. $\mathrm{br} /$ site/index.phpoption $=$ com_content\&view $=$ article\&id $=9162 \&$ Itemid=9>. Consultado del 10 julio de 2010 . 
CUT (2002), Resoluções da $10^{\circ}$ Plenaria Nacional da CUT. Disponible en versión digital en <http:// www.cut.org.br/documentos-oficiais>. Consultado el 14 de marzo de 2008.

CUT (2003), Resoluções da $8^{\circ}$ CONCUT. Disponible en versión digital en: <://www.cut.org.br/documentos-oficiais>. Consultado el 10 de Julio de 2008.

CUT (2005), Resoluções da $11^{\circ}$ Plenária Nacional da CUT. Disponible en versión digital en: <http:// www.cut.org.br/documentos-oficiais>. Consultado el 10 de Julio de 2008.

CUT (2006), Resoluções da $9{ }^{\circ}$ CONCUT. Trabalho e democracia: emprego renda e direitos para todos os trabalhadores e trabalhadoras. Disponible en versión digital en: $<$ http://www.cut.org.br/documentos-oficiais $>$. Consultado el 10 de Julio de 2008.

FNT (2005), Diagnóstico das relações do trabalho. Disponible en versión digital en: <http://www.mte. gov.br/fnt/DIAGNOSTICO_DAS_RELACOES_DE_TRABALHO_NO_BRASIL.pdf>. Consultado el 10 de junio de 2009.

NCST (2005), Carta de principios. Disponible en versión digital en: $<$ http://www.ncst.org.br/cartaprincipios.pdf>. Consultado el 10 de junio de 2009.

INTERSINDICAL (2006), Manifiesto. Disponible en versión digital en: $<$ http://www.intersindical.org. br/apresentacao.php.htm>. Consultado el 10 de junio de 2009.

RESOLUCIONES DEL PT. Desde enero de 2002 a enero de 2007. Material disponible en versión digital en: <http://www.pt.org.br/portalpt/documentos/resolucoes-29/pagina-1/>. Consultado el $14 \mathrm{de}$ marzo de 2008.

NOTAS DE PRENSA DE LA CGT. Desde enero de 2002 a enero de 2007. Material disponible en versión digital en: <http://www.cgtra.org.ar/htdocs/index.php?id_seccion=71>. Consultado el $14 \mathrm{de}$ marzo de 2008.

\section{Entrevistas realizadas por el autor:}

H. ACERREYGOR. Entrevista realizada en la ciudad de Buenos Aires, 26/05/2009.

A. ALIZEGUI. Entrevista realizada en la ciudad de Paraná, 05/05/2010.

D. AMOROSO. Entrevista realizada en la ciudad de Buenos Aires, 07/04/2010.

S. BARRADAS CARNEIRO. Entrevista realizada en la ciudad de Bahía, 08/07/2009.

S. A. BASTEIRO. Entrevista realizada en la ciudad de Buenos Aires, 15/05/2010.

J. BATISTA LEMOS. Entrevista realizada en la ciudad de São Paulo, 29/05/2009.

D. BECK. Entrevista realizada en la ciudad de São Paulo, 26/06/2009.

N. BECK. Entrevista realizada en la ciudad de Porto Alegre, 11/11/2003.

C. BERNAZA. Entrevista realizada en la ciudad de Buenos Aires, 29/11/2009.

A. BORGES. Entrevista realizada en la ciudad de São Paulo, 26/05/2009.

L. CHOINACKI. Entrevista realizada en la ciudad de Florianópolis, 01/06/2009.

R. DALLO. Entrevista realizada en la ciudad de Porto Alegre, 29/10/2003.

A. DATO. Entrevista realizada en la ciudad de Buenos Aires, 24/11/2009.

J. M. DE ALMEIDA. Entrevista realizada en la ciudad de São Paulo, 27/05/2009.

DR. ROSINHA. Entrevista realizada en la ciudad de Brasilia, 21/05/2009.

R. FALCÃO. Entrevista realizada en la ciudad de São Paulo, 03/07/2009.

J. GENOÍNO. Entrevista realizada en la ciudad de São Paulo, 06/07/2009.

G. GRANERO. Entrevista personal realizada en la ciudad de Buenos Aires, 16/04/2010.

A. HENRIQUE DA SILVA. Entrevista realizada en la ciudad de São Paulo, 26/06/2009.

L. R. HLEBOWICZ. Entrevista realizada en la ciudad de Buenos Aires, 27/04/2010.

G. HOFFMAN. Entrevista realizada en la ciudad de Curitiba, 08/06/2009.

M. E. LÓPEZ ARIAS. Entrevista realizada en la ciudad de Buenos Aires, 05/05/2010.

J. LOPEZ FEIJOÓ. Entrevista realizada en la ciudad de São Paulo, 26/06/2009.

R. LÓPEZ. Entrevista personal realizada en la ciudad de Rosario, 28/07/2010.

M. MARTINS. Entrevista realizada en la ciudad de São Paulo, 25/06/2009.

A. MENTOR. Entrevista realizada en la ciudad de São Paulo, 24/06/2009.

M. MESSIAS. Entrevista realizada en la ciudad de São Paulo, 26/06/2009.

D. MOREYRA. Entrevista realizada en la ciudad de Buenos Aires, 26/04/2010. 
R. MOUILLERON. Entrevista realizada en la ciudad de Buenos Aires, 05/05/2010.

N. MOURÃO. Entrevista realizada en la ciudad de Brasilia, 15/05/2009.

F. NENNA. Entrevista realizada en la ciudad de Buenos Aires, 25/03/2010.

C. NÉSPOLO. Entrevista realizada en la ciudad de Porto Alegre, 04/12/2003.

C. PEREIRA DA SILVA. Entrevista realizada en la ciudad de Porto Alegre, 10/10/2003.

T. PEREIRA DOS SANTOS. Entrevista realizada en la ciudad de Porto Velho, 25/05/2009.

J. C. PEREIRA SILVEIRA. Entrevista realizada en la ciudad de Porto Alegre, 8/11/2003.

H. PEREIRA. Entrevista realizada en la ciudad de São Paulo, 24/06/2009.

R. PEREYRA. Entrevista realizada en la ciudad de Buenos Aires, 13/04/2010.

H. H. PIEMONTE. Entrevista realizada en la ciudad de Buenos Aires, 16/04/2010.

J. PIUMATO. Entrevista realizada en la ciudad de Buenos Aires, 29/07/2010.

RANGEL. Entrevista realizada en la ciudad de Porto Alegre, 21/11/2003.

D. RICCI. Entrevista realizada en la ciudad de Buenos Aires, 13/04/2010.

E. RÍOS. Entrevista realizada en la ciudad de Buenos Aires, 10/09/2008.

A. ROSSI. Entrevista realizada en la ciudad de Rosario, 10/10/2008.

A. ROSSI. Entrevista realizada en la ciudad de Rosario, 28/11/2009.

S. RUEDA. Entrevista realizada en la ciudad de Buenos Aires, 15/10/2008.

A. SAAVEDRA. Entrevista realizada en la ciudad de Buenos Aires, 22/04/2010.

M. SANCHEZ. Entrevista realizada en la ciudad de Buenos Aires, 29/09/2008.

M. SANTOS COSTA. Entrevista realizada en la ciudad de Bahía, 01/06/2009.

Q. SEVERO. Entrevista realizada en la ciudad de Porto Alegre, 14/10/2003 y la ciudad de São Paulo, 05/07/2009.

Recibido: 27/12/2016. Aceptado: 02/03/2017.

Juan Lucca, "Tirios y Troyanos: sindicatos y partidos durante el gobierno de Lula y Kirchner". Revista Temas y Debates. ISSN 1666-0714, año 21, número 33, enero-junio 2017, pp. 137-160. 